\title{
Energy justice towards racial justice
}

\author{
Black and African American people face systematic disadvantages in energy costs and limited access to renewable \\ energy benefits. Addressing these disparities is an important part of achieving racial justice.
}

Therlon he COVID-19 pandemic and racial protests in response to the murder of George Floyd have highlighted systemic inequities affecting ethnic and racial minority populations. For example, in the US, Black and Latinx people have an increased risk of contracting the virus, and of experiencing severe illness in the case of infection $^{1}$. The disproportionate impacts of COVID-19 for communities of colour are not limited to the illness itself. COVID-19 is expected to increase the prevalence of energy poverty as households face higher energy bills from being at home more, particularly during the summer months, and unemployment that makes these bills more difficult to afford ${ }^{2}$. In this way, too, African American households are at greater risk, as they already face higher rates of energy poverty than other racial groups (they account for nearly half of energy-poor households in the $\mathrm{US}^{3}$ ) and they are more likely to receive disconnection notices and experience utility shut-offs ${ }^{4}$.

The higher rate of energy poverty among African Americans has been attributed to a history of racist housing policies that have segregated African Americans in low-resource neighbourhoods ${ }^{4}$.

Consequently, African Americans are more likely to live in older homes with structural deficiencies and poorly functioning energy infrastructure ${ }^{4}$. These energy inefficient homes require more energy to heat or cool to comfortable living conditions, resulting in a higher energy burden.

As examined by Dominic Bednar and Tony Reames in a Review in our May issue, the US has federally-funded energy programmes that ostensibly address energy poverty ${ }^{5}$. However, funding for the Weatherization Assistance Program (WAP), which provides eligible low-income families with cost-effective energy efficiency upgrades, pales in comparison to that for the Low Income Home Energy Assistance Program (LIHEAP), which provides energy bill assistance to subsidize high energy expenditures. This indicates a preference for short-term solutions based on a narrow definition of energy poverty focused on affordability (LIHEAP) over programmes such as WAP, which aim to provide a more sustainable, long-term solution with a broader range of benefits, including for public health ${ }^{5}$. Notably, it is programmes like WAP that would go toward addressing the consequences of structural racism - in the form of residential segregation policies - that have led to higher rates of energy poverty among African Americans ${ }^{4}$. In fact, it has been argued that weatherization and energy efficiency initiatives could be a form of restorative justice for this community ${ }^{4}$.

As Sanya Carley and David Konisky describe in a Review in this issue, the disproportionate prevalence of energy poverty within communities of colour is one of the inequities that could be perpetuated by the clean energy transition, assuming it increases the near-term costs of energy. However, justice considerations for energy transitions are not just about disproportionate burdens, but also disparity in the distribution of benefits, such as access to employment opportunities in the clean energy economy. Here, too, there is evidence of systematic disadvantage on the basis of race; only $8 \%$ of the US energy efficiency workforce is Black or African American, compared to the national average for the overall labour force of $12 \%{ }^{6}$.

There is also evidence of racial disparity in access to the benefits afforded by low-carbon technologies. For example, Black- and Hispanic-majority neighbourhoods in the US have significantly fewer rooftop solar photovoltaics (PV) installed, even after accounting for differences in household income and home ownership ${ }^{7}$.This suggests the possible influence of systematic racial and ethnic biases, such as less initial deployment of PV in minority neighbourhoods, which limits processes of social dispersion that promote more widespread PV adoption. This uneven distribution in deployment may in turn reflect a lack of diverse representation in decision-making at solar firms.

African Americans are not the only vulnerable group that must be considered to ensure just and equitable energy transitions. Indeed, many of the issues described above also apply to low-income groups, the elderly, those with disabilities, women and other minorities. Nor are energy justice and equity issues unique to the US. But vulnerable groups differ in the root causes of their vulnerability, which result in different susceptibility to adverse impacts and necessitate different solutions and protections.
For instance, a study in the southwestern US found that elderly people and those with disabilities had greater bill increases than non-vulnerable counterparts when moved to time-of-use electricity rates, whereas other vulnerable groups included in the study low-income, Hispanic, African American or households with young children - did not. Meanwhile, Hispanic households and those with disabilities experienced worse health outcomes on time-of-use rates ${ }^{8}$. Understanding how different forms of vulnerability manifest and interact with energy policies and programmes in different contexts is essential to avoid exacerbating existing injustices.

A clean energy transition will require innovation in renewable energy technologies, but for these to achieve their transformative potential the institutions and systems that support existing fossil fuel regimes must be dismantled, a process known as exnovation'. Similar exnovation is needed to pave the way for change to other societal systems currently under scrutiny. The COVID-19 pandemic may prove to be the kind of large-scale disruption that expedites this process. Racial justice considerations must be front and centre as society starts to imagine what the new normal will look like, in the energy sector and beyond.

Published online: 14 August 2020 https://doi.org/10.1038/s41560-020-00681-w

\footnotetext{
References

1. Oppel Jr., R. A., Gebeloff, R., Lai, K. K. R., Wright, W. $\&$ Smith, M. The fullest look yet at the racial inequity of coronavirus. The New York Times (5 July 2020); (https://www.nytimes.com/interactive/2020/07/05/us/ coronavirus-latinos-african-americans-cdc-data.html

2. Graff, M. \& Carley, S. Nat. Energy 5, 352-354 (2020).

3. Drehobl, A. \& Ross, L. Lifting the High Energy Burden in America's Largest Cities: How Energy Efficiency Can Improve Low Income and Underserved Communities (American Council for an Energy-Efficient Economy, 2016); https://www.aceee.org/sites/ default/files/publications/researchreports/u1602.pdf

4. Lewis, J., Hernandez, D. \& Geronimus, A. T. Energy Effic. 13, 419-432 (2020).

5. Bednar, D. J. \& Reames, T. G. Nat. Energy 5, 432-439 (2020).

6. US Energy Employment Report (US Department of Energy, 2020); https://www.usenergyjobs.org/ https://staticl.squarespace. $\mathrm{com} / \mathrm{static} / 5 \mathrm{a} 98 \mathrm{cf} 80 \mathrm{ec} 4 \mathrm{eb} 7 \mathrm{c5cd} 928 \mathrm{c} 61 / \mathrm{t} / 5 \mathrm{ee} 78423 \mathrm{c} 6 \mathrm{fcc} 20 \mathrm{e} 0$ 1b83896/1592230956175/USEER+2020+0615.pdf

7. Sunter, D. A., Castellanos, S. \& Kammen, D. M. Nat Sustain 2, 71-76 (2019)

8. White, L. V. \& Sintov, N. D. Nat. Energy 5, 50-60 (2020).

9. Davidson, D. J. Nat. Energy 4, 254-256 (2019).
} 